\title{
ANESTHETIC APPROACH OF A MORBIDLY OBESE PATIENT UNDERGOING SINGLE- STAGE BILATERAL THORACIC SURGERY.
}

Athina Siampalioti ${ }^{1}$, Maria Spyraki $^{1}$, Eleni Sintou ${ }^{1}$, Georgios Karpetas $^{1}$, Aurora Dinca $^{1}$

${ }^{1}$ Anesthesiologist, Critical Care and Anesthesia Department, University Hospital of Patras, Patras, Greece

\section{Background and aims}

The anesthetic management of morbidly obese patients constitutes a challenge for the anesthesiologist, as these patients demonstrate significantly high morbidity and mortality rates. We present a case of a morbidly obese patient undergoing bilateral thoracotomy under combined general and epidural anesthesia.

\section{Methods}

A 44 year old male with $\mathrm{BMI}=49 \mathrm{~kg} / \mathrm{m} 2$ and a medical history of arterial hypertension, diabetes mellitus, dyslipidemia and nephrectomy due to kidney cancer, underwent a bilateral thoracic surgery. Preoperative spirometry revealed: $\mathrm{FEV} 1=3,9 \mathrm{lt}(96 \%)$ and $\mathrm{FVC}=4,32 \mathrm{lt}(88 \%)$ while arterial blood gases (ABG"s) in room air revealed: $\mathrm{pH}=7,35, \mathrm{pCO} 2=36,7 \mathrm{mmHg}, \mathrm{pO} 2=72,5 \mathrm{mmHg}$.

Echocardiography revealed a suboartic stenosis and $\mathrm{EF}=60 \%$. We administrated general anesthesia with a double lumen endotracheal tube 39Fr, along with thoracic epidural analgesia (levobupivacaine $2 \%$ and fentanyl $2 \mu \mathrm{g} / \mathrm{ml}$ with a rate of $5 \mathrm{ml} / \mathrm{h}$ and a patient- controlled bolus lockout of $5 \mathrm{ml}$ every 15 min at T5-6 interspace. Basic monitoring, invasive arterial pressure measurement, Bispectral Index and Cerebral Oximetry monitoring (INVOS) were used.

\section{Results}

The patient was hemodynamically stable perioperatively, while no difficulty was observed during one- lung ventilation, for both lungs. Cerebral oximetry and BIS remained within normal limits (INVOS variation $<10 \%, \mathrm{BIS}=40-55)$. Postoperative $A B G " s$ indicated $(\mathrm{FiO} 2=35 \%), \mathrm{pH}=7,4, \mathrm{pO} 2=125 \mathrm{mmHg}$, $\mathrm{pCO} 2=38,2 \mathrm{mmHg}$ and VAS scores $<5$ under epidural analgesia.

\section{Conclusions}

Thoracic epidural analgesia has been proven to be beneficial and safe for the morbidly obese patients, providing not only quality and faster recovery (Aldrete score $>9$ within $45 \mathrm{~min}$ ), but also a reduction in ICU stay after high risk surgeries.

\section{References}

Improvement of recovery parameters using patient-controlled epidural analgesia for video-assisted thoracoscopic surgery lobectomy in enhanced recovery after surgery: A prospective, randomized single center study. Zejun $N$, Wei $F$, Lin L, He D, Haichen $C$. Thorac Cancer. 2018 Jul 27. doi: 10.1111/1759-7714.12820.

Managing post-thoracotomy pain: Epidural or systemic analgesia and extended care - A randomized study with an "as usual" control group. Tiippana E, Nelskylä K, Nilsson E1, Sihvo E, Kataja M, Kalso E. Scand J Pain. 2014 Oct 1;5(4):240-247.

Anesthesia for thoracic surgery in morbidly obese patients. Lohser J, Kulkarni V, Brodsky JB. Curr Opin Anaesthesiol. 2007

Feb;20(1):10-4.
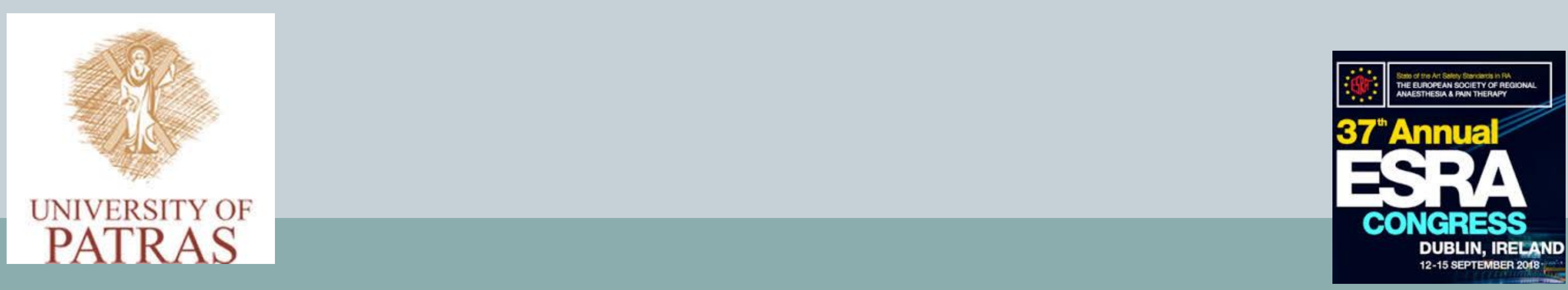